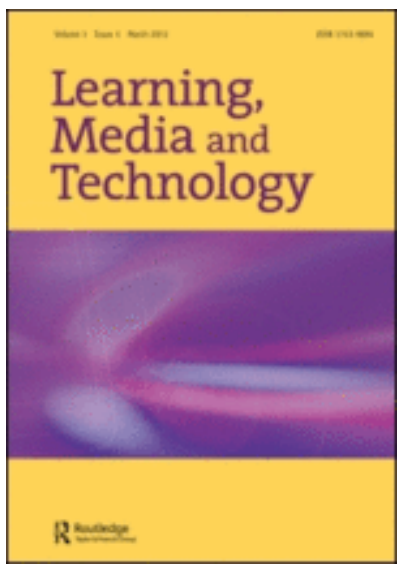

Negotiated, Contested and Political: The Disruptive Third Spaces of Youth Media Production

\begin{tabular}{|r|l|}
\hline Journal: & Learning, Media and Technology \\
\hline Manuscript ID & LMAT-2019-0186.R1 \\
\hline Manuscript Type: & Research Articles \\
\hline Keywords: & Videogame, Young People, Digital Literacies, Libraries, Twine \\
\hline \multicolumn{2}{|l}{} \\
\end{tabular}

SCHOLARONE ${ }^{m}$

Manuscripts 


\title{
Negotiated, Contested and Political: The Disruptive Third Spaces of Youth Media Production
}

\begin{abstract}
Traditionally media production with young people has been characterised by an aspiration to 'give voice' or 'empower youth' (Blum-Ross, 2017) but this core value is under threat. Recently, the rationale for undertaking youth media production has shifted to focus instead on enabling young people to acquire digital skills to serve the needs of rapidly changing creative industries (Blum-Ross and Livingstone, 2016); to be entrepreneurs in a gig economy. In this paper we share qualitative data from a young people's media production project run in libraries in a city in the United Kingdom where participants were invited to create videogames / stories. We adopt Potter and McDougall's (2019) notion of Third Spaces as negotiated, contested and political to enable us to identify the ways in which pedagogical choices of setting, software and style of facilitation combined to support young people's critical and creative engagement with digital media and society. We reframe notions of third spaces, seeing less a bridge between linguistic and cultural domains and instead arguing that Third Spaces are productively disruptive. We conclude by proposing a new set of pedagogical principles for critical reflection in the development and funding of digital media production with young people.
\end{abstract}

\section{Keywords:}

Third Spaces, videogames, youth, libraries, media production, storytelling, digital technology, agency, empowerment

\section{Figures:}

Figure One: Twine Game User Screen

Figure Two” Twine Game ‘Backend’ Interface

Figure One and Two are screenshots from the games made by children which we have permission to use via UoN ethical consent process. They are also publicly available in the libraries via games hubs. 


\section{Youth media production in the 21st-century}

The past twenty years have seen a growth in the use of media production in arts projects, youth work, makerspaces and libraries (Hobbs, 2019). In these contexts media production has traditionally been associated with voice, agency and democratisation particularly for marginalised groups (Dezuanni, 2011, Blum-Ross and Livingstone, 2016). Media production is also increasingly part of participatory and visual research methodologies in which young people are invited to represent their own experiences to wider audiences, rather than being represented by researchers. For example, in the field of critical disability studies, video has been an important medium for self-representation and the disruption of the existence of a 'single story' of disability (Rice et al., 2016).

Blum-Ross (2017, p.5) provides a useful critique of what she describes as the rhetoric of youth media production, demonstrating that young people's engagement with media production does not necessarily support empowerment. She argues that discourses of 'empowerment' are often used in youth media in ways that do not pay attention to the challenges of shifting from an 'abstract discourse to practical outcomes.' Hauge (2014) similarly argues that 'agency' needs to be reconceptualised to pay closer attention to current complex and affective events in youth media production. Rather than concede to the challenges of reconceptualising agency and voice, we suggest in this paper that research has an important role to play in the further development of digital media production pedagogies.

In the 21 st-century, the affordability and accessibility of digital technologies and highspeed internet has led to an expansion of opportunities for young people's media production. Increasingly, the focus of this work has been on developing a future workforce with digital skills (Facer, 2019). Blum-Ross and Livingstone (2016) caution against the way that media production has been reframed in neoliberal terms in relation to entrepreneurialism and express concern about what this might mean for young people. Facer (2019 p.3) challenges the dominance of future-focused narratives of education and technology, arguing that young people need opportunities to make and share stories in order to 'identify and articulate desires, hopes, fears and dreams for the future and to engage with the rich complexities of the present.' Indeed many in the field of literacy claim that making media is a matter of social justice and that those without access cannot be part of increasingly 
participatory cultures (Jenkins et al., 2006). Like Cannon (2018) we therefore suggest that digital media production should be embedded in school curricula, not to enable the preparation of a digitally skilled workforce but rather to provide all children and young people with an important context for critical and creative engagement with the world. However, in the UK the opportunity to embed digital media production is limited by national curriculum and testing strategies so that most of this work takes places outside school. Although, as in the case of this project, there is often pressure to provide informal activities for children which use art, media or sport to support formal learning rather than as activities which have an intrinsic value of their own.

Given the threat of the neoliberal skills agenda in both formal and informal settings, it has become imperative to better understand how youth media production pedagogies support storytelling that disrupts dominant narratives. Our purpose in this paper is therefore to share data from a youth media production project where young people made videogames in their local libraries. We adopt Potter and McDougall's (2019) concept of Third Spaces which enables us to pay attention to pedagogy and process in the broadest sense in relation to the library as a context, the choice of Twine as the software and the style of facilitation. We begin by reflecting on the way in which Thirdspace theory has come to inform research in relation to media, literacy and digital media production.

\section{Moving into Third Spaces}

Literacy scholars have turned to the concept of Thirdspace ${ }^{1}$ to make the case for valuing children's home literacies at school. Gutiérrez, (2008 p.43) conceptualised Thirdspace as a 'transformative space where the potential for an expanded form of learning and the development of new knowledge are heightened' and linguistic and semiotic resources are included in this conception. This idea has permeated other fields, for example, Adams (2009) suggests that libraries have the potential to act as 'third places' that is to say, physical places for learning which are not home or school, that could offer new forms of literacy activity, including videogame playing and production. Moje et al., (2004) and Pahl and Kelly (2006) conceive of Thirdspace slightly differently, as a pedagogic space which bridges a gap between home and

\footnotetext{
${ }^{1}$ Please note we adopt the form of expression of the theory as used by each respective author.
} 
school literacy domains and enables marginalised students to draw on their home knowledge to connect with more academic learning. Cannon, Potter and Burn (2018 p.118) see digital media production as a Thirdspace which renders the "boundary between home and school' more fluid. The nature of the analogy we use to understand and explain Third Space is less benign.

We return to Bhaba's (1994) original conception of the term where the 'other' or a third dimension, is brought into being by the existence of two dominant discourses entwining in momentary 'in-between thinking'. We imagine this otherness resulting from a moment of conflict; a moment in which meaning is contested, prompting negotiations which are inherently political. Potter and McDougall (2017) use the term 'working in the third space' as a way of recognising that under certain circumstances the existing habitus of home and school can intersect and be disrupted or reimagined. The reference to Bourdieu's (1990) concept of habitus is important. It is the habitus, the existing ways of thinking and doing things that are potentially disrupted or reimagined in Third Spaces. Third Spaces therefore transgress disciplines and traditional concepts about expertise and knowledge (Potter \& McDougall, 2019). This is to say that Third Spaces are not bridges over which ideas can flow together seamlessly, but instead can be imagined as sometimes dormant sometimes volatile, chemical elements which need heat, or light or physical proximity to react and be transformed. In moments of reaction and resistance, the cultural experiences of young people can become powerful and the hierarchies of learners can be disrupted. Potter and McDougall (2019) identify the need for Third Spaces to be 'negotiated, contested and political' to enable 'shape shifting' in relation to pedagogy and power and this has useful parallels with Butler's contemporary notion of agency as located not in the person but in 'a complex choreographed scene with many kinds of elements - social, material, human - at work' (in Bell, 2010 p151).

We therefore operationalise Potter and McDougall's (2019) conception of Third Spaces as 'contested, negotiated and political' in relation to the social, material and human contexts of digital media production. From Dahya's (2017) perspective, context is defined as the 'pedagogical design, setting, media genres, and technological tools as influential parts of the work young people complete (or abandon).' For Dahya, context also refers to the broader settings and interactions between factors that shape what young people produce and how they participate in digital media production practices. We therefore focus on the ways in which differing contextual elements combine and react in key moments to bring Third Spaces into 
being. In particular, we examine the way the social, material and human were at work in the libraries, the software and the facilitation that shaped the way the young people experienced the project. Before we do so, we provide a brief summary of the project and the methodological approach.

\section{The [Name of Project] Project}

[Name of Project] was a 12-month [Name of Funder] funded programme run in partnership with [Name of Libraries], [Name of Museum] and [Name of Initiative]. The programme, which consisted of 36 workshops and 4 further events in libraries across a city in the East Midlands, and was devised by library senior leaders and their partners in response to the ever-increasing popularity of videogames for young people. The library venues selected were predominantly located in economically disadvantaged boroughs of the city. The project aimed to examine how libraries could support young people to gain literacy and digital skills through the making of videogames.

Twine, a free to download piece of software, was used throughout the project as a tool for creating games/stories. ${ }^{2}$ Workshops were facilitated by staff from the National Videogame Arcade and often involved children working in pairs and groups to design their own game/story. Twine, an open-source programme, is used principally for generating non-linear stories, responsive narratives and basic games. It has an active online community through which many users share stories and ideas on various forums, as part of the social context for learning (Williamson \& Facer 2004).

\section{Methodology}

Young people were invited to take part in the project through online marketing, and in person via school recruitment visits and by library staff across six library sites located in disadvantaged communities. The project was freely available but the participants were asked to sign up through an online booking form which involved gaining

\footnotetext{
2 The texts made in Twine are narratives which offer the reader options - a blue or a red door. To go forward or go back. The author must plan for there to be consequences for every choice and it is possible to see how each narrative element relates to other - see figure 1 .
} 
parental consent. The only criteria that was used for recruitment was age which was set as 14-25. These participants were invited to complete two online questionnaires as part of their involvement in the workshops. The first young people's questionnaire, completed by 39 individuals, aimed to explore participants' pre-existing experience and knowledge of the workshops, including coding experience, literacy and reading interests. The second questionnaire, completed by 23 young people, sought to gain insight into participants' overall programme experience. Additionally, interviews with 20 young people and key programme staff were also conducted. Alternative methods, including a Twine version of the interview, were also produced to explore young people's experiences across different modalities. 12 workshop and event observations were also undertaken. The young people's game / stories produced in the workshops were then summarised for analysis. Interviews were transcribed and field notes summarised to facilitate discussion between the researchers and project partners. The particular focus of this paper emerged through the process of writing the evaluation and presenting the work internationally which led us to theorise the production pedagogies involved in the game / story design. An ethical approval process was followed so that participants were aware of the rationale for collecting data about their experiences of the project and their right to withdraw their involvement. The young people often wanted their authorship to be strongly flagged which was the case in the project dissemination, but not in our reporting of the project. To provide anonymity and to be consistent across sites, we have not given pseudonyms here but simply refer to types of participants - young people, facilitators and library staff.

In our analysis we used the notion of Third Spaces as negotiated, contested and political (Potter and McDougall, 2017, 2019) as a lens for identifying the ways in which social, material and human aspects of the context setting (libraries), the choice of software (Twine) and the style of facilitation produced moments of productive disruption. In our account of our analysis we provide a wide angle, overview of key issues that emerged alongside close up snapshot examples which enable a richer exemplification.

\section{i. Libraries}

Given the ubiquitous and historical public understanding of the role of libraries as providers of quiet spaces for selecting and reading books and accessing information, the presence of the project in these spaces was anticipated to be important. From 
the outset the material arrangements in libraries were contested. 'Business as usual' was interrupted by the introduction of new people into the space as one Librarian pointed out:

You are getting people who don't usually use the space to use the space. And you are going to get Joe Bloggs to walk in and interrupt it and that's fine because they also might find it interesting and we can share that interest with them.

Where the project took place in the main public arena of the library, the facilitators signalled its presence with posters and resources. We also observed the young people increasingly taking up spaces such as seating areas, marking them with their coats and bags and gathering up resources, mainly books and leaflets. The use of sound in games was clearly something the young people recognised as incompatible with the traditional practices of libraries. For example, one participant commented that it would be an unsuitable environment to come and play online shooter games. However, although all the library spaces were quiet at the beginning of the sessions we noticed some young people being increasingly more vocal, allowing their voices to resonate.

In sites where the project took place in the library, the daily routine was disrupted, establishing a different rhythm and ambience which meant that $4.00 \mathrm{pm}$ became the beginning of something rather than the end both for the young people and the library staff and users. By contrast, a particular issue arose in some libraries where the sessions took place 'in meeting rooms off the beaten path' as one facilitator suggested:

We didn't really interact with any other space. We were just in that computer room.

The 'sterile environment' away from the public library space limited the opportunity for any sort of disruption. Interestingly, when asked about the opportunity for videogames to be in libraries in the long-term the young people in these groups were hesitant:

But gaming here would just create more of a social atmosphere, whereas libraries are not that social ... you wouldn't say "I'm going to the library because I wanna play video games".

The use of rooms away from the main library space appeared to limit the extent to which the activity prompted moments of disruption which needed to be negotiated. 
Being in a space where negotiation is required, was not in our view something to be avoided but instead seemed highly productive.

The tensions that arose due to the disruption of the norm in material, social and human ways opened up the need for negotiation. Most of the library staff took an interest in the young people's progress, communicating with them and the facilitators and accommodating change. Indeed they became mediators who negotiated for the young people. For example, in one session an adult wanted the librarian to move the young people from the computers so that he could fill in some important official documents. This interaction attracted the attention of others, silencing the room and creating a strained atmosphere. The librarian took the opportunity to briefly explain the project and the need for the young people to use the space. Empowered by this validation the young people then volunteered to 'budge up' so that one of the computers they were using became available. The disruption to established human, material and social elements created a 'scene of agency' which established the entitlement of young people to be in libraries, using the computers and wifi to create videogames. As a result of this moment, those involved, embarked on a lively discussion in which videogame expertise was taken seriously and again disrupting the notion of the videogame as absent from libraries.

This moment can be seen as one in which a Third Space emerged due to the managed confrontation between those who are situated by the context as in opposition. A similar process takes place in documentary film-production focused on civic engagement and dealing with issues such as knife-crime, or stop and search (Goodman and Cocca, 2014) or radio broadcast (Soep, 2012) where young people create content which brings them into a discursive space with people who either share their concerns or are the cause of their concerns. Like Potter and McDougall (2017) we would suggest that this aspect of the Third Spaces of youth media production can happen in a school context but that giving young people have some choice in the topic of production and ensuring they encounter pertinent people and places is critical to establishing possibilities for negotiation and politicisation. Where projects are linked to formal learning goals or teacher-led civic engagement the opportunities for negotiating and contesting ideas may be limited.

Contesting and negotiating within the habitus (Bourdieu, 1990) of libraries became transformative, and in this sense political, enabling both the young people and the adult users to see libraries and perhaps each other in different ways. We are reading 
these as creating 'small p' political moments in which young people have opportunities for criticality in relation to their own context which creates the possibility of a wider civic engagement. For example, in the view of one Library Assistant the project was seen to have changed the 'feel' of the library:

Traditionally you associate the library with somewhere where you have to be quiet and where you can get your books. I think it's become more of a social hub now where people do numerous things.

For the young people who did not use the main library space, this possibility did not surface as readily. Working in the public space of the libraries determined the extent to which the young peoples' presence and the activity they were undertaking was open to being contested or negotiated. This in turn determined the extent to which they saw the spaces they were working in, as contentious. Where their presence was contested this was political and prompted critical thinking about what and who libraries are for.

\section{ii. The Affordances of Twine}

The choice of the software Twine, and its particular affordances, strongly determined the way the project unfolded. Affordances, as outlined by Gibson (1979) relate to what is made possible by the design of a text or tool. As we have described earlier, Twine is a piece of free software for creating game/stories which offer the reader/player choices and consequences. Many games creation projects with young people use Scratch, a programme designed to teach coding that is now widely used in the primary technology curriculum in UK schools. In this sense the choice of Twine contested implicit assumptions about the purpose of games-making, focusing the project more strongly on the stories the young people wanted to tell than on specific skills development relating to coding. This created a shift in pedagogy so that the young people were not being constructed as inexpert, because they were all experts in stories, especially as in this case, they were invited to draw on their experiences of popular culture.

Twine, is also a non-profit making, open-source programme with an active online community providing a wider social context for learning (Williamson \& Facer 2004). Using a tool which works in this way, counters the more entrepreneurial approach where learning to use a piece of software is seen as an accomplishment that distinguishes you from your competitors in the gig economy. Using open-source 
software in education presents young people with alternatives reasons for creating content. Indeed many games created in Twine have civic purposes, for example Depression Quest ${ }^{3}$ is an interactive story which explores self- management of depression. Interestingly, many of the game/stories dealt with serious or what the young people themselves called 'dark' issues, although some were darkly humorous.

Another way in which the choice of Twine contested existing socio-cultural and pedagogic practices, was in the way in which stories could be created collaboratively rather than individually as would usually be the practice in school. Although most texts are made with an audience in mind Twine creates moments where the games designer must explicitly plan for the responses of the reader / player:

I've learnt how to entice the reader, because normally I just think about the world (from my point of view). Now I know that you have to keep them interested as well.

Twine appeared to open a negotiated space in which the young people engaged with an imagined reader who may or may not share the experience of texts and everyday life. This is a complex, challenging space where the socio-cultural aspects of making meaning, usually an implicit process, become more tangible. We all draw on our experiences of life and of other texts (Kress, 2009) in our storytelling. Even the most original texts are original only, in relation to other texts that have gone before. Our previous narrative experiences may include games, films, books, comics, graphic novels as well as the everyday, but they entwine in our memories in ways that are difficult to pin down. Authors do not always remember where ideas came from and how they evolved. However, the visual and spatial design of Twine makes the narrative elements and their connections to each other visible and the process more explicit :

Storytelling is about getting your point across ... And voices as well - I can imagine a voice but I can't type a voice to make people think that's what they sounded like.

\footnotetext{
${ }^{3}$ https://the-quinnspiracy.itch.io/depressionquest
} 


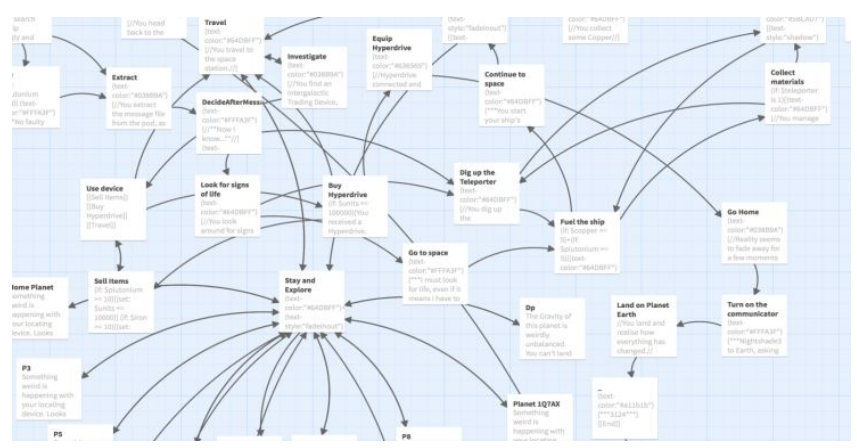

Figure One: Twine Game ‘Backend’ Interface

By clicking between playing, coding and writing the game / story and checking for coherence, the designer or author of the story steps into and out of the diegetic world. This resembled the fantasy play of young children who step out of the fictional world to plan and direct each other. We observed pairs of young people, working together in pairs with their heads so close together it would not have been possible to put a piece of paper between them. They frequently moved in and out of the story and the design process enabled intense collaboration.

The process of creating a Twine story was therefore markedly different to the way the young people created texts in school and this was regularly commented on. This resulted in a different sort of agency to emerge which involved the participants in a creative flow which only disintegrated due to creative differences or in order to test out the effect of the work in progress. This was again seen as different from school where you could be asked to stop to do something else at any moment. This ability to have some autonomy about when to stop and when to restart prompted the sort of critical distancing that is needed to create a coherent finished text. For example, one pair of boys asked others to play their game /story and realised that they were creating far more of the bad or dark side of their story than good. They decided they needed to add to the 'good' pathways but reflected that it was more fun 'being evil.' This also provided an opportunity for what we would suggest is a small $p$ political consideration of morality and the way in which it is presented in popular media.

Another way in which participants were able to exercise autonomy and thus agency was in the development of story ideas. It is important to note that this relates to facilitation too, but we are focusing here on the way Twine invites or even requires multiple narrative threads and in this context we observed that knowledge and experience of popular culture and everyday life became entangled. Although it was certainly the case that ideas from different domains flowed together, this did not 
seem to fit the common thirdspace analogy of a bridge so that a chemical reaction seemed to be a better fit. For example, in the game / story, 'Inferno', the author began the story with the protagonist hearing a screaming voice while walking home from school. The player / protagonist then realises that the city around him is on fire. Using the affordances of Twine the author then provided the options of looking around the city or running home to rescue family members. The author described the detailed emotions and behaviour of the protagonist and drew on both fiction and nonfiction to describe living in a gang-ridden, post-apocalyptic America but there a quite a contrast between this and the way family feature:

"Wade kicks the door down to save his sister and mum. He rushes upstairs towards the shouting. As he steps in he notices he is not being affected or weakened by the burning heat of the fire or the smoke entering his lungs. Instead he feels more powerful and more energised, like nothing he has ever felt. The heat is not bothering him at all... continue to save his family." The protagonist develops super-hero powers that allow him to save his family and other innocent civilians from evil. The hero's characterisation is fictional yet his actions are depicted through everyday behaviour such as caring for his family.

The author draws on references to popular culture, such as the characterisation of super-heroes but these collide or react with personal experiences of family responsibilities, resulting in an exploration of themes such as death, social anxiety, survival and the spontaneity of life. As Inferno's storyline progresses further, the player is presented with a series of encounters such as saving a mother and toddler from a burning helicopter, finding an escape vehicle, escaping from a gang of terrorists and having to live in an armoured vehicle for 25 days. Through these dangerous events, Wade gathers strength and saves more and more people. At first glance this story may appear to be a fairly straightforward redesign of existing, generic ideas but it is important to acknowledge that this enabled an incorporation of self into the story which disrupted some of the ways a post-apocalyptic world has been represented in previous fictional texts. The ideas that emerge connect with those that have gone before both in terms of the way they are similar (the protagonist as hero) and the way they are different (in the focus on the risk to mum and sister. The hero gains strength with each risky task he completes but he also faces ethical dilemmas more associated with the everyday than the superhero genre. For this young person, bringing together experiences of home and family with popular culture became an important opportunity to save the world. 
At risk of clumsily rendering this experience more concrete than it was, we would argue that here the political emerges through the way in which the story developed. The more complex ideas about society and responsibility were not foregrounded either by the author of the facilitators. The story context of burning buildings resonated with those the author would have seen in both news and fiction and it is significant that he places himself in the story as the hero who can save the world. On the surface, the story may seem generic, but we see aspirations of empowerment in ways that it is important for facilitators to be alert to.

In summary, creating a game / story in Twine easily enabled the authors to check how the ludic elements of the story were working for the audience was important. This disrupted a traditional focus in written stories of checking for spelling and grammar and as a result the young people demonstrated a strong commitment to the idea of creating a coherent story. A further key affordances of Twine requires the author to draw on a wide range of story ideas from different sources in order to offer multiple narrative threads, providing a productive disruption of conventional linear narrative structure. In negotiating these disruptions the young people had to combine and juxtapose ideas in ways that shaped the creative process; they collaborated and took on new roles as games designers and user testers but also as powerful central protagonists in their own fictions.

\section{iii. Facilitation:}

Despite the formality of a library setting, the facilitation of the project took a distinctly informal approach, which we would suggest served to contest the everyday pedagogic strategies the young people experienced at school. When asked what planning had gone into their workshops the three workshop leaders replied that their key role was about getting people comfortable with the basics, giving them the tools first and then getting them to express their ideas. Enabling the young people to develop their own stories was key to the facilitation.

One game/story 'First Date', was created by one participant but shared throughout the devising process with the other group members who acted as potential players. 
She says your sense of humour is terrible.

You get ammoyed that she said you have a bad sense of

humour

Suck it up because she is pretty hot but has really bad taste in movies

Figure Two: Player Screen of First Date

With only one pathway to the final ending of achieving a date, many group members played the game, followed a 'red herring pathway' and failed, at great amusement to the author who made use of personal experiences of first dates as well as ideas based on 'reality' television programmes and, in particular, 'Love Island.' Simply by requiring the young people to draw on their own socio-cultural story experiences, the activity broke with school practices where 'there is always a starter sentence' and a set of expectations which limit the extent to which young people can connect with their own experiences of stories and in particular the ways these stories have their own histories in terms of genres, authors and form. As we have argued, having free choice to decide the focus of their Twine game/stories was key to creating agency and autonomy. A myriad of narratives about outer space survival, a student's first day at university, internet chatrooms and cryptic curses plaguing humanity were developed and remixed. Themes explored included gender, politics and everyday life. Popular genres included mystery, science fiction, horror, drama, romance and adventure. Inviting home engagements with texts into a creative process often results in the appearance of transgressive elements, and this is seen in animation production with children especially which may be humorous but at odds with what might be expected in school writing. In this context young people are able to place difficult ideas at a safe distance to laugh and exercise some agency over them (Author 1, 2012). This is markedly different from contexts in which young people are asked to create media about a challenging contemporary issue, for example climate change, which also diminishes the possibility for humour and distancing.

Again as we observed in relation to the affordances of Twine, despite process involved writing of different sorts, it was interesting to see how the accuracy of spelling, grammar, and language use was very explicitly put to one side with the support of the workshop facilitator: 
It helps them gain confidence. I think for me, I am not focused on grammar or spelling when I facilitate the sessions. I tell the participants to get their ideas out onto the page and then deal with that other stuff later.

In fact, the facilitators often referred to themselves as being 'rubbish' at spelling, undermining some of the ways that they might be seen as more expert than the participants.

We also observed a relaxed approach to getting started or planning. No one was hurried along, although some did hurry, so the pace varied for each pair. Some of the young people did plan on paper first but most went straight to the screen and worked in a quite intuitive but also collaborative way. The cue from the facilitator was to have fun, to be playful and to take risks. This was clear in terms of both ideas generation for characters, plots and settings but also written or coded expression:

l've learnt that it can actually be anything. On Twine you could write 'ok' and it'd be classed as a story.

This resulted in overt instruction only being given, when requested in order to progress with an aspect of the storytelling which placed a much higher value on the stories, rather than on learning a particular skill. Dezuanni (2011) uses Derrida's (1978) notion of free play in the context of skills acquisition in digital media production to highlight the ways in which pedagogies of production can create the possibility of 'scenes of agency' (Butler, 1990) and this connects to the pedagogies of other literacy domains such as writing, where, for example, an aspect of grammar might be overtly taught within a wider situated literacy practice rather than a decontextualised grammar exercise (Barton and Hamilton et al, 2000).

The style of facilitation contested school experiences and enabled boundary crossing. At one point one young person gave each of the facilitators nick-names based on 'Scooby Doo'. These were acutely observed, funny and shared with us, rather than said in our absence. Usually name calling such as this would be challenged but here it was a marker of the way in which power relations had become less stringent.

Potter and McDougall (2018) refer to the way in which media production establishes more 'permeable membranes' between educators and students' expertise. Drawing 
on popular culture in literacy-related work, often disrupts the usual power relationships in terms of who has expertise in particular cultural texts (Buckingham and Sefton-Green, 2005) and thus expertise is not, as often experienced by young people in schools, the sole domain of the teacher. The notion of who was an expert was certainly fluid and negotiable. This often manifested in the sharing and discussion of favourite and well-known texts but also niche texts which facilitators knew less about.

In one case the facilitators also worked closely with a library staff member who became a co-facilitator. The presence of a member of the library staff member who was also learning to use Twine provided a further challenge to hierarchies of learners. as soon as they could, did his own research and used internet tutorials in order to extend his knowledge.Working with staff who were learning to use the software alongside them again resulting in a disruption of hierarchies.

Throughout the workshops a keen interest was taken in the young people's game stories. They were taken seriously, played and responded to. The young people were encouraged to talk about the games and other stories they liked and this enabled those working with people they had not met before to connect by sharing likes and dislikes. Often at the start of the session the facilitators would say their stories could be 'fun or weird' signalling an openness to their tastes and preferences whatever they would be about and the young people responded enthusiastically to this more open brief:

Yes. It don't always have to be like a weird story. It could be like a scary one, a funny one or a sad one. A happy one. Or it could be all mixed together. In this space what counts as a good, funny, serious or well-told story is contestable and does not reference set criteria relating to curricula but does echo other texts and their creators. Older peers were often experts, whom younger group members looked to for encouragement and affirmation. Younger participants were able to establish their credentials through their expertise in games or other media, at times blurring the edges of existing boundaries of year group or physical maturity.

It was reiterated often, that the possibilities for the young people's game/ stories were endless and that everything could be edited, developed and improved in order to make it work. This open-endedness also established the project as a sociable and collaborative space with an open exchange of ideas often in evidence, as one Librarian commented: 
I also think it did encourage them to use their imaginations and it helped them because it let them bounce ideas off each other.

These social exchanges of ideas were key to the way [Museum] staff were able to support the young people, to take risks in their creative work and develop their confidence without any fear of being laughed at, as highlighted by this library staff member's reflection:

I saw confidence develop in the workshops, and the children were chatting and meeting new people with similar interests, laughing and really enjoying sharing what they had done.

Rather than closing down the banter that often characterised communication between the young people, the facilitators navigated these interactions respectfully. Sometimes workshop leaders were on the sidelines helping someone with their story, sometimes they were the butt of jokes: 'you see what I have to put up with' and sometimes they gently joined in to help negotiate disagreements. There were lulls to this atmosphere of banter however and in each observation there were frequent moments where the participants were fully immersed in the creation of their own games.

\section{Conclusion}

Whilst digital media production does not inherently disrupt power relations or ensure young people's experiences are valued, it has the potential to. In determining pedagogical approaches that make this more likely Potter and McDougall's (2019) notion of Third Spaces as contested, negotiated and political provides a useful framework for understanding the different ways the broader context provides opportunities for productive disruptions. In this project, the disruptions resulted from a library environment where it was possible for the activity to disrupt the usual day to routines and activities. The choice of software, Twine, provided new ways to think about creating stories which heightened awareness of the reader and of narrative structure but also of online spaces which are not monetised. The facilitation disrupted the young people's experiences of school where their stories are predominantly created in writing, individually and where there is always a 'starter' which limits choice. The simple act of enabling the young people to select their own ideas for stories was perhaps the most productively disruptive aspect of the project because it 
encouraged them to take ideas from one form and create them in another which proved to be useful in terms of critical distancing and reflection. What is more, the ability to write themselves into fictional texts and popular genres played an important role in disrupting and appropriating those very texts, for their own uses.

This is not to say that all media production activity should use Twine or be set in libraries or facilitated in an informal style. However, there are some principles for digital media production which contribute to the extent to which they become Third Spaces and we would recommend that educators, funders and practitioners consider how these principle heighten the possibility for challenge, negotiation and criticality to:

- enable digital media production to disrupt (or make its presence felt) in both material and digital environments;

- enable young people to exercise agency especially in relation to story ideas, encouraging them to draw on what they enjoy, and are collectively or individually expert in;

- enable young people to try out software which is free rather than used to promote monetisation and is supported by a community of storytellers;

- think of conflict as potentially productive and negotiation as potentially political.

If we are to resist the discourse of media production as simply workforce skills development, it is important to be able to identify the ways in which the process can provide a Third Space which is distinct from and therefore challenges existing ways of doing things. This study therefore provides a set of principles as provocations to encourage policy-makers, practitioners, funders and educators to reflect critically on their rationale for digital media production with young people and urges them to pay attention to the potential for production pedagogies to create Third Spaces which take empowerment seriously.

\section{References}

\section{Author One}

Adams, S. S. (2009). The case for video games in libraries. Library Review, 58(3), 196-202.

Barton, D., Hamilton, M., IvaniÚc, R., \& Ivanič, R. (Eds.). (2000). Situated literacies: Reading and writing in context. Psychology Press. 
Bell, V. (2010). New scenes of vulnerability, agency and plurality: An interview with Judith Butler. Theory, Culture \& Society, 27(1), 130-152.

Bhabha, H.K. (1994) The Location of Culture. London, Routledge.

Blum-Ross, A. (2017). Voice, empowerment and youth-produced films about 'gangs'. Learning, Media and Technology, 42(1), 54-73.

Butler, J. (1990). Gender trouble: Feminism and the subversion of identity. New York: Routledge.

Blum-Ross, A. \& Livingstone, S. (2016). From youth voice to young entrepreneurs: the individualization of digital media and learning. Journal of Digital and Media Literacy.

Buckingham, D., Pini, M. \& Willett, R. (2007). 'Take back the tube!': The discursive construction of amateur film and video making, Journal of Media Practice, 8:2, 183201.

Bourdieu, P. (1990). The Logic of Practice. Cambridge: Polity Press.

Cannon, Michelle; Potter, John \& Burn, Andrew (2018) Dynamic, Playful and Productive Literacies, Changing English, 25:2, 180-197.

Cannon, M. (2018). Digital Media in Education: Teaching, Learning and Literacy Practices with Young Learners. Basingstoke, Springer.

Derrida, J. (1978). Writing and Difference. London. Routledge

Dezuanni, M. L. (2011) Youth media production and technology skills acquisition : opportunities for agency. In Fisherkeller, JoEllen (Ed.) International Perspectives on Youth Media : Cultures of Production and Education. Peter Lang Publishers, New York.

Facer, K. ( 2019) Storytelling in troubled times: what is the role for educators in the deep crises of the 21st century?. Literacy, 53: 3-13.

Geertz, C. (2008). Thick description: Toward an interpretive theory of culture. In The cultural geography reader (pp. 41-51). London, Routledge.

Gibson, J. J. (1979). The Ecological Approach to Visual Perception. Boston: Houghton Mifflin.

Goodman, S., \& Cocca, C. (2014). " Spaces of Action": Teaching Critical Literacy for Community Empowerment in the Age of Neoliberalism. English teaching: Practice and critique, 13(3), 210-226.

González, N. Moll, L. C. and Amanti, C. (2006). Eds. Funds of knowledge: Theorizing practices in households, communities, and classrooms. London, Routledge.

Gutiérrez, K. D. (2008), Developing a Sociocritical Literacy in the Third Space. Reading Research Quarterly, 43: 148-164. 
Gutiérrez, K.D., Baquedano-López, P. Alvarez, H.H. \& Chiu, M. (1999). Building a culture of collaboration through hybrid language practices, Theory Into Practice, 38:2, 87-93.

Hauge, C. (2014). Youth media and agency, Discourse: Studies in the Cultural Politics of Education, 35:4, 471-484.

Jenkins, H., Clinton, K., Purushotma, R., Robison, A. J., \& Weigel, M. (2006). White paper Confronting the Challenges of Participatory Culture: Media Education for the 21st Century. Berkeley, US: MacArthur Foundation.

Kress, Gunther. (2009). Multimodality: A social semiotic approach to contemporary communication. London: Routledge.

OFCOM. 2018. Children and parents: media use and attitudes report. Ofcom, London. Viewed April 1, 2019 at https://www.ofcom.org.uk/ data/assets/pdf file/0024/134907/Children-and-ParentsMedia-Use-and-Attitudes-2018.pdf

Moll, L., Amanti, C, Neff, D. \& Gonzalez, N (1992). Funds of Knowledge for Teaching: Using a Qualitative Approach to Connect Homes and Classrooms, Theory into Practice, 31. p132-141.

Moje, E.B., Ciechanowski, K.M., Kramer, K., Ellis, L., Carrillo, R. \& Collazo, T. (2004), Working toward third space in content area literacy: An examination of everyday funds of knowledge and Discourse. Reading Research Quarterly, 39: 3870.

Pahl, K. \& Kelly, S. (2005), Family literacy as a third space between home and school: some case studies of practice. Literacy, 39: 91-96.

Potter, John \& Julian McDougall. 2017. Digital media, culture and education: Theorising third space literacies. London: Springer.

Rice, C. Chandler, E. Harrison, E. Liddiard K. \& Ferrari, M (2015). Project Re•Vision: disability at the edges of representation, Disability \& Society, 30:4, 513-527.

Soep, E. (2012). The digital afterlife of youth-made media: Implications for media literacy education. Comunicar: Revista Científica de Comunicación y Educación, 19(38), 93-100.

Williamson, B. \& Facer, K. (2004). More than 'just a game': the implications for schools of children's computer games communities, Education, Communication \& Information, 4:2-3, 255-270. 


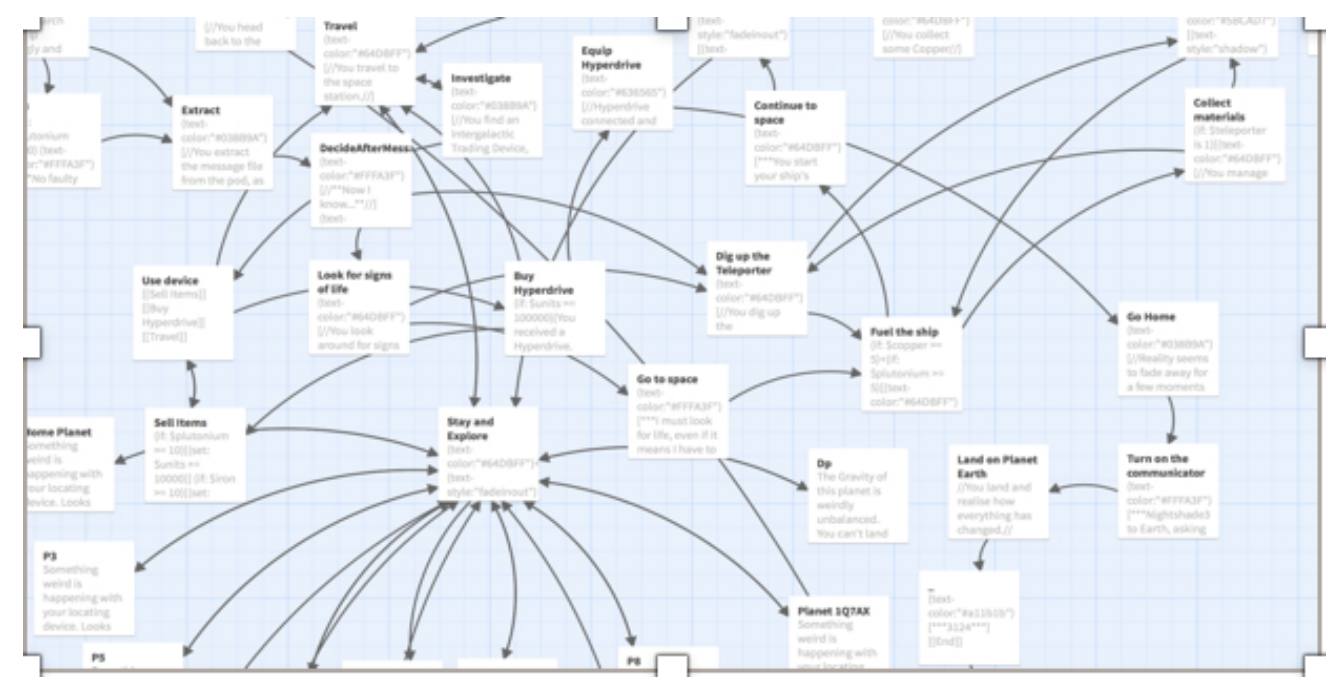

1

24

25

26

27

28

29

30

31

32

33

34

35

36

37

38

39

40

41

42

43

44

45

46

47

48

49

50

51

52

53

54

55

56

57

58

59

60

URL: http://mc.manuscriptcentral.com/Imat 


\section{She says your sense of humour is terrible.}

\section{You get annoyed that she said you have a bad sense of} humour

Suck it up because she is pretty hot but has really bad taste in movies

\section{2}

